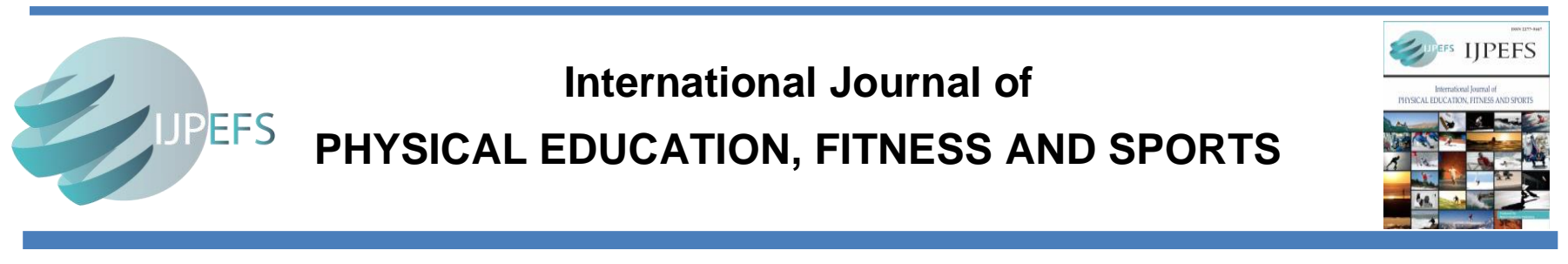

\title{
Karate in MMA Analysis of Lyoto Macida's Career and Fighting Style
}

Received : $18^{\text {th }}$ Sep 2017 Accepted : $29^{\text {th }}$ Sep 2017

www.ijpefs.com

DOI: 10.26524/ijpefs 1734

\section{Velimir Jeknić a *, Goran Kasum b, Miloš Stojković a}

a Abu Dhabi Police College, Department of Sport, Abu Dhabi, UAE

b University of Belgrade, Faculty of Sport and Physical Education, Belgrade, Serbia

*Corresponding Author: Ph: +971-566699681: Email: velimirjeknic@yahoo.com

\begin{abstract}
Fighting as a sport represents the phenomenon of civilization which involves refined and legalized fight between two people with strict limitations. Although we find roots of MMA in Ancient Greece, officially it is a relatively new sport, created at the end of the $20^{\text {th }}$ century. It united all well-known martial arts into one system, and this paper reflects on the distinguished representative and "modern ambassador" of karate, Lyoto Machida. Machida had 29 official MMA fights in various organizations, and in 2009 he became the world champion at the Ultimate Fighting Championship, the world's best MMA organization. The importance of winning this championship is great for karate and it lies in the confirmation of the applicability of karate in real fight. The aim of this paper is to describe his successful career in sports and to look into the fighting style which brought him glory.
\end{abstract}

Key Words: unorthodox style / ufc / martial arts

\section{Introduction}

Martial arts represent a worldwide phenomenon which have outgrown their national boundaries and areas of influence and have become a global phenomenon. Martial arts originate from the Far East, but the practice that exists today is global and substantially altered compared to the original content and practice in its native cultures [1]. Martial arts are increasingly deviating from traditional values, being transformed in the direction of commercialization.

Lyoto Machida is the man who verified karate as a skill and restored its dignity. He is the living proof that karate is a weapon which can be well used in the hands of the master. Machida raised and promoted karate as some other MMA fighters did for their skills: Karo Parisyan for JUDO, Mirko Filipovic for KICKBOXING, Dan Severn for WRESTLING, Fedor Emelianenko for SAMBO and, of course, Royce Gracie for BRAZILIAN JIU-JITSU.

Mixed martial arts (MMA) is one of the most intricate sports in the world [6].In MMA striking, chocking and grappling are allowed. There are several organizations which bring the fighters together and organize matches, and their rules only slightly differ. In all variants, the rules are designed so that they have only minimal restrictions regarding the allowed effects. Hits with head, hits in the spine, throat, nape and genitals, as well as pushing fingers in the eyes and biting are forbidden. This makes it possible for the fights to be very dynamic and uncertain, and the possibility for athletes who perform different martial arts to compete brings a lot to the attractiveness of the sport $[2,3]$.

The UFC is the largest MMA (mixed martial arts) organization in the world. It organizes fights for the title of the official world champion. The fights organized by this association take place in a cage popularly called the octagon. Martial arts have existed for thousands of years, as well as the competitions in this sport (since $1185 \mathrm{BC}$ and the ceremony on the funeral of Achilles' friend Patroclus, ancient boxing and wrestling, Pankration of the Ancient Greece, introduction of competitions in eastern arts, Vale Tudo, modern Pancrase), but they reached the greatest flourishing in history during the first 20 years of the existence of the UFC, and these fighters today are the latest and the best models. MMA today is very popular all over the world; It is one of the main forms of entertainment, according to 
television broadcasts around the world and the amount of money paid to the fighters.

Karate - There is a great number of definitions which describe karate and they mostly concentrate on three characteristic aspects of karate: art, skill, sport. Karate has changed through these three aspects, so today we have three forms of practicing karate: traditional, sport and practical.

Traditional karate is a form of practicing karate where the basic form of the karate technique is KIHON (the standard school model of the traditional technique). In the method of training, the primary place has a method of symbolic martial arts (KATA). Additionally, the method of strengthening the impact surfaces (TAMESHIWARI) is also present. Sparring is very little represented; only in YAKUSOKU KUMITE (agreed sparring). This concept of practicing karate has a specific philosophical and psychological foundation.

Modern - sport karate represents a transformed form of the traditional concept of practice, which was created at the beginning of the $20^{\text {th }}$ century, with the first public demonstration of karate, and it especially developed after the Second World War, by introducing competitions. The basic feature of this form of karate is competition.

The third form of karate, which is included in self-defense programs and special physical education, can be referred to as practical karate. Lately, the techniques of karate are becoming increasingly important in the training program for persons involved in jobs requiring special martial arts (security, police, army...). The form and application of the technique of karate are conditioned by the specifics of situational tasks (attack, interception, defense against various types of attacks, exercises on how to get released when being held, etc.) [4].

Karate in $M M A$ - As each martial art evolved and followed new tendencies, so did karate because it also started combining different martial arts. The modification of techniques and gaining knowledge through other martial arts put karatekas into the position to try MMA. Fighters who originate from karate and who made it to the very top of the UFC are Chuck Liddell (Kempo rarate), Bas Rutten (Kyokushinkai karate), Georges St-Pierre (Kyokushinkai karate) and Stephen Thompson (Kempo karate).

\section{Lyoto machida}

Lyoto Machida, son of karate master Yoshizo Machida, is one of the top-ranked mixed martial arts competitors in the world. After earning his Karate black belt at the age of thirteen, he mastered a number of other martial arts disciplines, including Sumo and Brazilian Jiu-Jitsu. Combining techniques from various disciplines to form an unusual and highly effective fighting style, Machida took the martial arts world by storm, defeating legendary mixed martial artists such as BJ Penn, Rich Franklin and Tito Ortiz [5]. His name is the synonym for karate in MMA. He made karate to be appreciated again in the world where mixture of styles, strength and brutality prevails.

\section{Anthropometry:}

Height: $1.85 \mathrm{~m}$

Weight: $84 \mathrm{~kg}$

Arm range: $188 \mathrm{~cm}$

MMA record: total -29

Wins - 21 (by knockout 9, by submission 2, by decision 11)

Losses - 7 (by knockout 2, by submission 2, by decision 3)

Biography - Lyoto was born in Salvador (Bahia) as the third son of Shotokan karate master Yoshizo Machida, the head of the Brazilian branch of the Japan Karate Association. He won a number of amateur karate tournaments, including the 2001 Pan American Karate tournament. He also began training Sumo at the age of 8 and Brazilian jiu-jitsu at the age of fifteen. In 2000, he participated in Brazilian Sumo championship in the $115 \mathrm{~kg}$ division. Later he became Brazilian champion twice, and he was a runner-up in the South American Championship in Sumo. He defeated the world champion in Brazilian jiu-jitsu, the American fighter Rafael Lovato Jr. at the L.A. Sub $\mathrm{X}$ tournament. In addition to his Sumo and Karate achievements, he has a College degree in Physical Education.

\section{MMA career}

When he decided to dedicate his life to fighting, Machida went to Thailand to study Muay Thai, and then to Japan to study wrestling. He met the legendary professional wrestler and MMA pioneer Antonio Inoki in Japan under whose management he began his career in mixed martial arts. At the age of 24, in his professional debut, at the manifestation organized by New Japan Pro Wrestling in Tokyo, on $2^{\text {nd }}$ May 2003 he defeated Kengo Watanabe by a unanimous decision of the judges. In his second fight, he defeated Stephan Bonnar by technical knockout in the event promoted by Jungle Fight in Manaus (Brazil). On December 31 st 2003, he took part in Inoki's annual event Inoki Bom-Ba-Ye 2003, where he fought Rich Franklin in a catchweight bout in which both men weighed $97 \mathrm{~kg}$. In front of over 40,000 fans at the Kobe Wing Stadium in Kobe (Hyogo, Japan), Machida defeated Franklin via TKO in the second round. He knocked Franklin down with punches in head throwing him on the floor, which forced the referee to stop the fight at the end of the first minute of the second round. On 14th March 2004, 
at the K-1 Beast in Niigata he beat Michael McDonald (Canadian kickboxer in his MMA debut) by forearm suppression in the first round. On $22^{\text {nd }}$ May 2014, at the K-1 MMA ROMANEX in Saitama Super Arena he defeated his colleague karateka (kyokushin) Sam Greco by split decision of the judges. Despite the fact that both fighters have striking skills, the fight was mostly carried out on the ground, where Machida controlled the match. On 26 ${ }^{\text {th }}$ March 2005 in Saitama at Hero's 1 manifestation Machida fought the UFC champion B.J. Penn in an openweight match. Machida weighted $102 \mathrm{~kg}$, while Penn weighted $86.5 \mathrm{~kg}$. Machida won by a unanimous decision.

\section{UFC career}

Machida made his UFC debut in the preliminary bouts of the UFC 67 against Sam Hoger and won by a unanimous decision. This was followed by his debut at the UFC 70 where Machida beat David Heath again by a unanimous decision. After that he faced a Judo practitioner and Pride Fighting Championship veteran Kazuhiro Nakamura at the UFC 76. Machida won by a unanimous decision. Nakamura was later tested positive for marijuana. At the UFC 79, Machida faced Rameau Thierry Sokoudjou, a highly ranked Judo practitioner making his UFC debut after two quick convincing victories over Pride veterans Antonio Rogerio Nogueira and Ricardo Arona. Machida made the first fight break in his UFC career by defeating Sokoudjou with an arm triangle choke in the second round. Machida's next fight was at the UFC 84 where he faced former UFC light heavyweight champion Tito Ortiz. Machida frustrated Ortiz with lateral movement, counterstrikes and successful defense against takedowns. In the closing minutes of the third round Machida knocked Ortiz down with a knee to the body. As Machida was trying to finish the fight before the time was up, Ortiz almost succeeds in a triangle choke. Machida managed to escape and win by a unanimous decision of the judges (all judges scored the fight $30-27$ in his favour). Machida had defeated all his opponents with more intelligent fight, but, in the UFC as a way of entertainment it is not enough to be invincible. A fighter, besides his opponents, has to think of image as well, and many people commented that Machida had too many tactics, that he was not aggressive enough and that he avoided fighting in his matches.

Lyoto knew what had to be done in order to win over the audience. He was aware that he was not going to win a title without an attractive performance. At the UFC 94, until then undefeated (both 14-0) Thiago Silva had a bad tactics from the very beginning because he had constantly been following Machida. Chasing him, he became an easy target for Lyoto's counterstrikes. Machida showed his wild side by knocking him out and winning the Knockout of the Night award. The commentators greeted the knockout as a real step in building the image of a potential champion. Since then, more and more people started watching him and he started receiving more and more fans. Machida's English improved, which gave him the opportunity to connect with the audience more easily. His previous poor English was seen as a marketing failure. Afterwards, Machida faced the light heavyweight champion Rashad Evans at the UFC 98. In another clash of undefeated fighters Machida knocked Evans out with a flurry of punches in the second round. Machida became the new UFC Champion.

Besides the champion belt, his performance that night earned him Knockout of the Night award with a $\$ 60,000$ bonus. This fight continued his series as undefeated in MMA (16-0) and it was at the same time Evans's first defeat. After the knockout, during the interview with Joe Rogan inside the cage, Machida said: "Karate is back! Machida Karate!". Many fans have since then called his style "Machida Karate". Winning the championship title was the result of the fact that Machida had not been knocked out in the first 15 battles in MMA, he had not been defeated, and he had not even lost a single round. And what is even more significant is that he received far less strikes than all UFC fighters with similar number of matches. Machida was supposed to face Quinton Jackson for the first title defense, but Jackson decided to be coach in the tenth season of The Ultimate Fighter instead. Maurício "Shogun" Rua, Pride's 2005 champion, was then selected as the challenger. The title defense took place on $24^{\text {th }}$ October 2009, at the UFC 104 when Machida defeated the 5 round match by a unanimous decision of the judges. All three judges scored 48-47 in Lyoto's favour, stating that he "had set the more damaging strikes throughout the fight" and was the more "effective aggressor".

Out of the three judges, Hamilton gave Machida rounds 2, 3 and 4. Peoples and Rosales each gave Machida the first three rounds. One of the judges (Nelson Hamilton) said in the interview after the match that he did not have a good overview of the majority of events during the $4^{\text {th }}$ round and that after having watched the video he realized that he would have judged the round in Shogun's favour.

All in all, since the decision was unanimous, the subsequent change in the scoring would lead to a split decision of 2-1, but still in Machida's favour. Hamilton also said that the commentators had led the viewers to believe that Shogun undoubtedly won the fight, but in fact the fight was very uncertain and very difficult for scoring for all three judges. In spite of this, most of the audience (who did not hear the 
commentator) booed the decision after it was delivered, expressing their support for Rua. Authors of a number of sports websites and magazines also claimed they felt that Rua should have won. On the other hand, there were also MMA fighters who supported the judges' decision and Lyoto's victory. Among them were several of Machida's training partners, including Antônio Rodrigo Nogueira, Anderson Silva, Junior dos Santos, José Aldo and Rafael Cavalcante. A FightMetric analysis of the fight suggested that Rua had been more aggressive and had landed more strikes to the head and legs than Machida, while CompuStrike reported that Rua landed almost twice as many strikes as Machida did. Both FightMetric and CompuStrike explicitly stated on their websites that they are not authorized to judge MMA events, and are merely organizations which track fighters' activities.

Because of the controversial decision, on $8^{\text {th }}$ May 2010, at the UFC 113 in Montreal (Canada), Machida and Rua faced each other again, seven months after their first fight. It was a much anticipated rematch. Both fighters started aggressively and scored significant points in striking exchanges, with Machida scoring two takedowns during the round. Rua showed strong defense on the ground, spinning to attempt a kneebar before both fighters returned to their feet. 3 minutes and 30 seconds after the beginning of the first round Rua swerved to avoid Machida's left hand and landed a powerful counter overhand in the tempest, which knocked Machida down. Rua then took the full mount position and continued to knock Machida out. 3 minutes and 35 seconds after the beginning of the first round Rua became the new light heavyweight champion, with Machida suffering his first MMA career loss.

Machida faced Quinton "Rampage" Jackson at the UFC 123. The decision about the winner of the match eventually came to the scoring of the first round because there was a unanimous agreement over the other two rounds in which the judges decided that Jackson won in the second and Machida in the third (most dynamic).

During the first round Lyoto landed several leg kicks and some counter punches, while Rampage predominantly landed from the clinch, utilizing heel strikes against Machida's feet and punches to Machida's side. Both Compustrike and Fightmetric records showed that Rampage out-struck Machida when counting strikes such as elbow strikes to the thigh (clinch strikes), while Machida landed more strikes during the standup exchanges. Due to the fact that Rampage scored a lot more minor strikes and Machida was superior in middle-distance exchanges, calculations showed that the first round was tie. In the second round, Compustrike and Fightmetric records showed that Rampage was the "more engaged" fighter, and he also scored a takedown. The cleanest and most significant strike in the second round was an uppercut, which was another argument that he should win the second round. In the third round, Machida landed a counter left gyaku tsuki that stunned Rampage, followed by a burst of punches, left leg and knee kicks that backed Jackson into the fence of the octagon. When Rampage tried to retaliate, Machida scored a takedown, eventually gaining full mount position and attempting several armlocks. At the end of the third round, Rampage was declared the winner by a split decision of the judges (29-28, 29-28, 28-29) which many considered to be controversial. Fighters such as Anderson Silva, Randy Couture and Mauricio "Shogun" Rua stated in their interviews a few days later that they thought that Machida had actually won the fight. In the interview with Jo Rogan right after announcing the winner, Rampage expressed that the fairest thing would have been to organize a rematch, as he felt he had lost the fight.

However, since the UFC President Dana White personally felt that Rampage won the fight, he denied the possibility of a rematch. This generated some controversy, as White had previously given the opportunity for a rematch to Mauricio "Shogun" Rua despite the unanimous decision of the judges to proclaim Machida for the winner.

In January 2011, the UFC President Dana White put a lot of pressure on Machida stating that in order to continue to be a fighter in the UFC organization he must win the next match, in which Machida was set to face the UFC Hall of Famer Randy Couture. Machida defeated Couture at the UFC 129 in Toronto by knocking him down with a jumping front kick (crane kick/tobi mae geri), earning the Knockout of the Night award. Dana White commented that Machida's performance against Couture put him back at the top of the division, but stated that he still was not ready to fight for the title again. Machida was then offered to fight Rashad Evans at the UFC 133, replacing the injured Phil Davis. However, the match was not held because Lyoto's team asked for more money than the UFC President was willing to pay. Tito Ortiz competed instead of him. Another Machida's fight was cancelled, this time because Phil Davis had not fully recovered from his knee surgery.

His next match took place on $10^{\text {th }}$ December 2011 at the UFC 140 against Jon Jones for the title in the Light Heavyweight division, despite the fact that he had lost two out of the last three matches. After the first round, in which Machida was better in the fight "on his feet", Jones moved the fight to the ground in the second round and made a big cut on the challenger's head. After the doctor's intervention the 
fight continued. Jones soon caught Machida in a standing guillotine. After a few seconds the referee separated them and Machida fell down unconscious.

On $4^{\text {th }}$ August 2012, Lyoto faced Ryan Bader in Los Angeles (California) at the UFC on Fox 4. He won by a knockout 1 minute and 32 seconds after the beginning of the second round.

On $3^{\text {rd }}$ August 2013, he faced Phil Davis in Brazil in a fight in which the judges unanimously proclaimed Davis as the winner.

In 2013, Machida moved to the middleweight division. He defeated Mark Munoz. Head kick KO cancelled the fight in the first round.

In his second fight in the middleweight division on $15^{\text {th }}$ February 2014, Machida defeated Gegard Mousasi in a 5 round fight, with each round lasting for 5 minutes, by a unanimous decision of the judges.

On $5^{\text {th }}$ July 2014, Machida lost his match against the division champion Chris Weidman by a unanimous decision of the judges.

Machida next faced C.B. Dollaway on 20th December 2014 at the UFC Fight Night 58. Machida won the fight via TKO only 62 seconds into the first round after landing a body kick that dropped Dollaway.

Machida faced Luke Rockhold on $18^{\text {th }}$ April 2015 at the UFC on Fox 15. He lost the fight via submission in the second round.

In his next fight Machida faced Yoel Romero on 27th June 2015 at the UFC Fight Night 70. After a fairly competitive first two rounds, Machida lost the fight via knockout in the third round.

At the age of 39, Machida is preparing for his next professional fight against Derek Brunson on October 28, 2017 at UFC Fight Night 119.

\section{Titles and accomplishments}

UFC Light Heavyweight Championship (One time);

One successful title defense vs. Maurício Rua (UFC); Knockout of the Night (Four times) vs. Thiago Silva, Rashad Evans, Randy Couture and Mark Muñoz (UFC);

- Fight of the Night (Three times) vs. Jon Jones, Gegard Mousasi and Chris Weidman (UFC);

- Performance of the Night (One time) vs. C.B. Dollaway (UFC);

- 2011 Knockout of the Year vs. Randy Couture (Sherdog Awards);

- $\quad$ Mixed Martial Arts Hall of Fame (Sherdog Awards);

- $\quad 2009$, Fighter of the Year (Black Belt Magazine).

\section{Analysis of Lyoto Machida's fighting style}

Machida uses a unique, unusual fighting style in MMA which combines elements from different martial arts. He was praised and criticized for his way of winning matches by the decision of judges. His style is mainly based on Shotokan karate (black belt $3^{\text {rd }}$ day) and Brazilian Jiu-Jitsu (black belt), but he also integrates Wrestling and Sumo techniques. Often described as elusive, Lyoto relies on cautious and precise counterstrikes which frustrate his opponents into making mistakes. Machida has earned considerable respect and affection from MMA fans, fighters, and commentators for his effectiveness and ways of winning fights. From probably the most complex fighting skill in the standing position (karate), Lyoto Machida easily adopted the knowledge of boxing or Muay thai, which is very difficult the other way around. Machida does not fight at the distance of a Boxer or Muay thai fighter. He fights on Karate distance and he strikes from there. It is easy for him to shorten the strikes when the situation requires so, but his opponents cannot prolong their strikes. In non-karate styles, fighters are taught to strike from short distance. As they cannot increase the range of the strike, they must come closer and thus they put themselves into a position to be a target, and Lyoto uses that to counterstrike. Lyoto has a black belt in BJJ. Joe Rogan (host of the UFC performances and martial arts expert) says about Machida: "Technique before strength, tactics before aggression. The most intelligent way of fighting is the way Machida fights. What should be achieved in MMA? You need to do as much damage as possible, and get out the least damaged. Nobody does it better than Machida. He is not just a fighter, he is a true martial artist".

Stance, guard and movement - Lyoto Machida's stance is longer, wider, deeper and he constantly tries to be farther away from his opponent. Machida mainly uses the south pole stance - the right hand and leg are forward, but he changes stance and strikes from the second guard, which is another aggravating circumstance which his opponents must think about. The range of his hitting techniques is large, so from the right guard he can do: gyaku tsuki, "overlaying", mawashi geri (jodan, chudan, gedan), knee kicks, cleaning ... From the left guard he can do "overlaying" (oi tsuki), mae geri, ushiro geri, boxing techniques... Machida can thank his father, who taught him karate, for his superior movement. UFC experts say that he has "the best footwork", which makes him elusive.

Foot kicks - Lyoto Machida's foot kicks come from Shotokan karate. He uses Mae geri, Ushiro geri, Mawashi geri, Tobi mawashi geri, Tobi mae geri. The difference between his foot kicks and those of the other fighters who we watch in MMA is that they make a step before the kick, and Machida kicks from his position, which makes Machida's kicks faster, more sudden, more precise and therefore more 
difficult to defend. Machida mainly strikes with the talus of his foot while others mostly hit with the lower shin. Also, Machida does not only use agonist (such as kickboxers), but also antagonist muscles, which reduces the inertial force, he inserts the antagonistic braking element that significantly reduces the force of the strike but increases the accuracy and allows him to return to the stance and guard he had had before the strike (as if he did not hit at all), while fighters who do not use antagonists find themselves in disadvantage in case of failure often turning their back to the opponent under the influence of the great inertial force (strong agonist action and the minimal effect of the antagonist) or slowly returning to the combat position. In short, Machida strikes the mawashi geri (jodan, chudan, gedan) while others use kicks (high, middle, low).

Punches - Machida's punches are different because they are mostly straight, and he uses elbows, hooks, uppercuts much less than his opponents. His arms technique is based on gyaku tsuki (alone or connected) and when the distance requires it, he adjusts to the situation and performs hooks. He was resented by the experts for the fact that he did not return his hands on his chin, but lowered them after hitting, while his opponents saw this as their chance and his weakness (explained by the lack of a hook in karate). He was often seen to return his hands to his hip after a strike.

Combining techniques - As the content of complex techniques and scheduled sparring, combining techniques is very common in karate. As Machida was training karate since he was three years old, it was not difficult for him to combine techniques in fights, most often with the aim that the first strike is feint and that the next one hits the target, or that the first shortens the distance and that the second (or even the third) causes the damage. The most common combinations are: leg-arm strikes, straight linking of the hand strikes (more gyaku tsuki), calf kick - punching.

Leg-arm connecting - Machida's connection of leg and arm strikes is not classical, as we are otherwise accustomed to seeing in kickboxing and MMA. The fighters generally have the following combinations: the front direct and then strike a low kick, two punches and a leg in the body or head... In most cases leg follows arms. The situation is different with this fighter. Machida kicks and immediately punches, or even combines kicks with two punches. He does not take a swing when kicking; he uses antagonist muscles, and thus preserves the necessary stability for the hand technique. When other fighters strike a kick followed by a punch, it is usually a hook or a similar punch, while Machida uses Kizami tsuki. The reason for this is that others always try to do as much damage as possible with a kick, while Machida kicks to make the distance so that he can make a "point" quickly with his hand.

Hands connection - When he is not "in the fire", Machida can connect punches very efficiently, which are based on 2 or 3 gyaku tsukis, because this is the most efficient way to reach his opponent's head, not giving him a chance to make a counterstrike. If the second strike does not hit the target, the third one does.

\section{Machida's significant moves}

Calf kick - Through his different techniques Machida also uses calf kick in the following variants: when he performs calf kick to knock down his opponent; calf kick as shortening of the distance and disturbance of the balance (front leg) and then strikes gyaku tsuki and - when he interrupts the opponent with gyaku tsuki and then use calf kick for throwing.

Knee strike (jap. Hiza geri) - Machida does a knee strike from the right guard, when he punishes his opponents for their careless approach due to the lack of attention or as a counterstrike.

"Overlaying" (punch after removing the opponent's front hand) Machida does this in two ways:

- When he is threatened by his opponent or feints with the front direct (strikes gyaku tsuki) and

- When he wants to surprise a passive opponent due to the lack of attention (strikes oi tsuki)

Gyaku tsuki (straight left) Machida uses the opponent's force (inertia) and he intercepts him in the form of gyaku tsuki into the head (sometimes the body) of the opponent.

\section{Conclusion}

Lyoto Machida has shown what karate has to offer in the octagon: great footwork, surprising and quick strikes, a variety of techniques (fist, foot, elbow, knee, calf kick...), distance management. He brought the true karate - with its virtues and faults: weaker striking power, not putting the hands back in the protection of the head after the attack, but on the hip, etc. He proved that the claim "There is no better skill, but better master" to be true. In the game in which he competes there are a lot of skills, so he himself is the master of several battlefields. Machida has in some way confirmed karate as a skill, karate has once again shone, but we should be aware that Lyoto Machida would have been anonymous in the MMA world that had not learn Wrestling, BJJ and Boxing. Lyoto Machida is an innovator and promoter of Karate in the MMA. The results say one thing, and part of the audience still thinks that Machida is a boring fighter. After Muhammad Ali and Mike Tyson even Vladimir Klyuchko is boring to the audience. 
According to the authors' opinion, this is pure evolution - from the foolish destruction of the opponent and themselves, to the victories with minimal damage suffered.

\section{References}

[1] Cirković, Z. (2006) Teorija borenja. Fakultet sporta i fiziĉkog vaspitanja, Beograd.

[2] Cirković, Z., Jovanović, S., Kasum, G. (2010) Borenja. Fakultet sporta i fiziĉkog vaspitanja, Beograd

[3] Filipović, A. (2011) Borilačke veštine između istoka i zapada. Malagma, Beograd

[4] Jovanović, S. (1992) Karate 1 - teorijska polazišta. Fakultet sporta i fiziĉkog vaspitanja, Beograd.

[5] Machida, L. Krauss, E., Cordoza, G. (2010) Machida Karate-do Mixed Martial Arts techniques. Victory belt publishing.

[6] Penn, B., Krauss, E., Gordoza, G. (2007) Mixed martial arts, the book of knowledge. Victory belt publishing. 